\title{
Organik yetiştirilen Trakya İlkeren üzüm çeşidinin verim ve kalite özelliklerinin incelenmesi
}

\author{
Investigation of yield and quality characteristics of the organically grown Trakya \\ İlkeren grape variety
}

\author{
Nazan BALBABA \\ Kahramanmaraş Sütçü İmam Üniversitesi, Türkoğlu Meslek Yüksek Okulu, Bitkisel ve Hayvansal Üretim Bölümü, Kahramanmaraş \\ Sorumlu yazar (Corresponding author): N. Balbaba, e-posta (e-mail): dogar@ksu.edu.tr
}

\section{MAKALE BİLGİSI}

Alınış tarihi 01 Haziran 2020

Düzeltilme tarihi 26 Eylül 2020

Kabul tarihi 28 Eylül 2020

\section{Anahtar Kelimeler:}

Organik bağc1lık

Sürme oranı

Salkım ağırlığ

T terbiye şekli

Y terbiye şekli

\begin{abstract}
ÖZ
$\mathrm{Bu}$ araștırma, iki farklı terbiye şekli ile üç farklı göz yükü seviyesi uygulamasının Trakya İlkeren üzüm çeşidinin verim ve kalite özellikleri üzerine etkisini belirlemek amaciyla üç y1 süreyle yürütülmüştür. Bütün göz yükü seviyelerinde ilk $500 \mathrm{~g}$ budama odunu ağırlı̆̆ için 20 adet göz bırakılmış sonraki ilave her $500 \mathrm{~g}$ için Kontrol göz yükü uygulamasında 10 adet, 1 . Göz yükü (1GY) uygulaması için 5 adet ve 2 . Göz yükü (2GY) uygulaması için ise 15 adet göz bırakılmıştır. Süren göz sayısı 2GY seviyesi uygulanan omcalarda; salkım sayısı ise Y terbiye şeklinde ve $2 \mathrm{GY}$ uygulamasında daha yüksek düzeyde elde edilmiştir. Verim miktar Y terbiye şeklinde denemenin 1. yıl ve 2. yılında $9763 \mathrm{~g}$ ile $19168 \mathrm{~g}$ olarak saptanmıştır Ayrıca göz yükleri bakımından 2GY uygulamasında 1. yıl 10845 g, 2. yıl 19693 g ve 3. yıl $14097 \mathrm{~g}$ verim elde edilmiştir. Salkım ağırlığı, $\mathrm{Y}$ şekli verilen omcalarda, denemenin 1. 2. ve 3. yll boyunca sirasiyla; $210 \mathrm{~g}, 279.7 \mathrm{~g}$ ve $364.4 \mathrm{~g}$ olarak belirlenmiștir. T ve Y terbiye șekli uygulanan omcalardan elde edilen üzümlerde antioksidan aktivite düzeyi benzer olarak saptanmıştır. Şıra özellikleri bakımından bütün uygulamalar ve yıllara göre farklı sonuçlar kaydedilmiştir. Bu sonuçlara dayanarak, Trakya İlkeren üzüm çeşidi için Y terbiye sistemi ve 2GY seviyesinin önerilebilmesi mümkün gözükmektedir.
\end{abstract}

\section{ARTICLE INFO}

Received 01 June 2020

Received in revised form 26 September 2020

Accepted 28 September 2020

\section{Keywords:}

Organic viticulture

Shooting rate

Cluster weight

T type trellis

$\mathrm{Y}$ type trellis

\begin{abstract}
This research was carried out for 3 years in order to determine the effect of two different training types and three different bud load levels on the yield and quality characteristics of the Trakya IIlkeren grape variety. In all of the bud load levels, 20 buds were left for the first $500 \mathrm{~g}$ pruning weight and for each additional $500 \mathrm{~g}$ pruning weight. 10 more buds left for control; 5 more buds left for first bud load and 15 more buds left for second bud load. Number of the burst into buds in $2 \mathrm{GY}$ treatments of the grapevines and cluster number was obtained higher level in the form of $\mathrm{Y}$ training and $2 \mathrm{GY}$ treatments. The yield was determined as $9763 \mathrm{~g}$ and $19168 \mathrm{~g}$ in the 1st and 2nd years of the trial in the form of $\mathrm{Y}$ training. In terms of bud loads, $2 \mathrm{GY}$ treatment yielded $10845 \mathrm{~g}$ in the first year, $19693 \mathrm{~g}$ in the second year and $14097 \mathrm{~g}$ in the third year. In Y-shaped vines, during the 1st, 2nd and 3rd years of the experiment, respectively; bunch weight has been determined as $210 \mathrm{~g}, 279.7 \mathrm{~g}$ and $364.4 \mathrm{~g}$. The antioxidant activity level was found to be similar in the grapes obtained from the vines with $\mathrm{T}$ and $\mathrm{Y}$ shapes. Different results were recorded according to all treatments and years in terms of must. Based on these results, it seems possible to recommend $\mathrm{Y}$ training system and $2 \mathrm{GY}$ level for Trakya İlkeren grape variety.
\end{abstract}

\section{Giriş}

Dünya üzüm üretimi son verilere göre, 9.9 milyon ha alanda 74.2 milyon ton olarak gerçekleşmiştir. Bağ alanı bakımından 939.283 ha ile İspanya 1. sirada yer almakta, Türkiye ise 416. 907 ha ile Çin ve Fransa'dan sonra 4. sırada bulunmaktadır (FAO 2020). Üzüm üretimi bakımından; Türkiye 3.9 milyon ton ile Çin, İtalya, ABD, İspanya ve Fransa'dan sonra 6. sirada yer almaktadır. Dünya üzüm ihracatında Şili, 1.2 milyar \$ ihracat geliriyle 1. sirada iken, Türkiye üzüm ihracatında 2017 y1lında 195 milyon \$ gelir elde edebilmiştir. Ülkemiz diğer ülkelerle kıyaslandığında ihracat bakımından ancak 13. sırada yer alabilmektedir (FAO 2020). 
Ülkemizde son verilere göre, 1.9 milyon ton sofralık üzüm, 1.5 milyon ton kurutmalık üzüm ve 463 bin ton şaraplık üzüm olarak toplam 3.9 milyon ton üzüm üretilmiştir (Tüik 2020). Sofralık üzüm üretimi bakımından Çin 9.4 milyon ton ile 1 . sırada, Hindistan 2.7 milyon ton ile 2. sirada üzüm üretimi ile yer alırken Türkiye 1.9 milyon ton ile 3 . sirada bulunmaktadır (Index mundi 2019).

Terbiye şekli verim, kalite ve maliyeti doğrudan etkilediğinden üzerinde durulan konulardan biridir. Asmalarda yapılan çalışmalar, sürgünlerin yukarı doğru büyümesi ile kışlık gözlerin verimliliğinin arttığını göstermiştir. Ağaoğlu (1973), sürgün gelişme yönünün verimlilik üzerine etkisini inceleyerek yukarı doğru büyüyenlerde salkım sayısı ve tomurcuk oranının daha fazla olduğunu belirlemiştir. (Karataş ve Ağaoğlu 2005)'da asmanın verimliliği ve gelişimi üzerine sürgün gelişme yönünün bilinmesinin terbiye şeklinin seçimi konusunda önemli olduğunu vurgulamıştır. Asma başına çubuk sayısı bir önceki yılın budama düzeyine, bağlı olup, bu da asmanın gelişimi ve sürgünlerde var olan salkım sayısını doğrudan etkilemektedir. Verim artışı, verimli göz sayısının artışı nedeniyledir (Christensen ve ark. 1994). Üzümlerde kalite de, doğrudan veya dolaylı olarak asmaya verilen terbiye şeklinden etkilenmektedir. Verim artarken kalite düşmemesi temel yetiştiricilik hedefleri içinde yer almalıdır.

Sofralık üzümlerde verim ve kaliteyi doğrudan etkileyen önemli temel konulardan birisi de asmaların budanması sırasında bırakılan göz sayısına, yani asma şarjına bağlı, ürün yükü konusudur (Winkler ve ark. 1974; Ahmedullah ve Himmelrick 1990; Ergenoğlu ve ark. 1991). Bazı araştırıcılar tarafindan kapasitesine uygun, az veya daha fazla göz veya ürün yükü uygulamalarının etkisi incelenmiştir. $\mathrm{Bu}$ araştırıcılardan Gök Tangolar ve ark. (2015) çalışmasında Narince üzüm çeşidinde farklı göz yükü uygulamalarının etkisini incelemiştir. Buna göre üzüm örneklerinde şeker, organik asit ve antioksidan aktivite bakımından farklı göz yüklerine göre çok fazla bir değişim gerçekleşmemiştir. Howell ve ark. (1991) ise farklı terbiye sistemlerinde farklı budama yükleri uygulayarak kalite özelliklerini araştırmışlardır. Kontrol, az göz yükü ve fazla göz yükü uygulamaları arasında omca başına verim artışının fazla göz yükü uygulanan omcalarda daha yüksek düzeyde olduğunu belirlemişlerdir.

Deneme alanında uygulanan organik bağcılık toprak biyolojik aktivitesini, biyolojik çemberi ve biyo çeşitliliği artıran ve teşvik eden bir üretim sistemidir (Mulero ve ark. 2010). Organik üzüm üretiminin temel amacı insan sağlığını ve doğal gübrelerle toprağın biyolojik aktivitesini korumaktır (Zafrilla ve ark. 2003).

Ülkemizde organik bağcılık faaliyetleri giderek artmaktadır. Bu kapsamda 2018 y1lı itibariyle organik olarak üretilen toplam üzüm miktarının 112 bin ton olduğu belirlenmiştir. Aynı yıl organik üretilen toplam ürün miktarı (organik tarıma geçiş süreci dahil olmak üzere) 2.3 milyon ton olarak kaydedilmiştir. Buna göre toplam organik ürün miktarı içinde üzüm üretim değeri yaklaşık \%4.8 civarındadır (Tarım ve Orman Bakanlığı 2019).

Kırmızı üzümlerin antioksidan aktivitesi fenolik ve flavonoid bileşiklerin kapsamı ile ilgilidir. Üzüm çeşitlerine bağlı olarak fenolik bileşik düzeyinin artması ile antioksidan aktivite seviyesi yükselmektedir (Luque-Rodríguez ve ark. 2005). Fitokimyasallar bakımından zengin olan üzümde bulunan antioksidan kapasite pek çok hastalığa neden olan serbest radikallere karşı güçlü bir etki sağlamaktadır (Wongnarat ve Srihanam 2017).

$\mathrm{Bu}$ çalışmanın amacı, organik yetiştirilen Trakya İlkeren üzüm çeşidinde $T$ ve $Y$ terbiye şekli verilen omcalarda farklı göz yükü seviyelerinin uygulanarak etkilerinin araştırılmasıdır. Çalışma sonucunda uygun terbiye şekli yanında, uygun bir göz yükü seviyesinin önerilmesi düşünülmüştür.

\section{Materyal ve Yöntem}

$\mathrm{Bu}$ araştırma, Çukurova Üniversitesi Ziraat Fakültesi Araştırma ve Uygulama Bağında 1103 P Amerikan Asma Anacı üzerine aşılanmış 10 yaşlı Trakya İlkeren çeşidiyle 2.25 x $3.5 \mathrm{~m}$ aralıklı oluşturulan bir deneme parselinde 2013, 2014 ve 2015 y1llarında yürütülmüştür. Asmalarda gövde yükseklikleri 130 $\mathrm{cm}$ olan $\mathrm{T}$ ve $\mathrm{Y}$ terbiye şekillerinin etkisi incelenmiştir.

\subsection{Terbiye şekilleri}

Denemede uygulanan terbiye şekilleri aşağıda belirtilmiştir:

1) $\mathrm{T}$ şekli; yüksekliği $1.90 \mathrm{~m}$ olan bir $\mathrm{L}$ demiri üzerine çapraz monte edilmiş $1 \mathrm{~m}$ genişlikte bir demir ile bunun yaklaşık $40 \mathrm{~cm}$ aşağısından $40 \mathrm{~cm}$ aralıklı delinmiş ikinci bir 40 $\mathrm{cm}$ genişlikte çapraz demirden oluşmuştur. 40'ar cm aralıklı teller tutunma; $1.50 \mathrm{~m}$ yükseklikteki alt demirin iki tarafindan geçirilmiş iki tel ise yatırma teli olarak kullanılmıştır. Yatırma telleri üzerinde 4 adet sabit kol (kordon) oluşturulmuştur.

2) Y şekli; direklerin yerden $1.30 \mathrm{~m}$ yüksekliğine $\mathrm{V}$ şeklinde bir parçanın monte edilmesi ile destek sisteminin oluşturulduğu bu terbiye şeklinde, $\mathrm{V}$ demirinin kol uzunlukları $100 \mathrm{~cm}$, üst açıklığı ise $150 \mathrm{~cm}$ olmuştur. $1.50 \mathrm{~m}$ yükseklikte çekilen iki tele kollar yatırılırken, üstteki tellere sürgünler bağlanmıştır.

Her iki terbiye şeklinde göz yükleri çubuk ağırlıklarına göre aşağıdaki gibi belirlenmiştir:

1) Kontrol göz yükü: İlk 500 g çubuk ağırlığı için 20 göz ve sonraki her $500 \mathrm{~g}$ için $10 \mathrm{göz}$ daha bırakılarak (Winkler ve ark. 1974; Ahmedullah ve Himmelrick 1990; Çelik 2007)

2) 1 . Göz yükü (1GY): İlk 500 g budama ağırlığı için 20 ve sonraki her $500 \mathrm{~g}$ için 5' er göz bırakılarak

3) 2. Göz yükü (2GY): İlk 500 g için 20 ve sonraki her 500 $\mathrm{g}$ için 15' er göz bırakma şeklinde oluşturulmuştur.

Terbiye şekilleri ile göz yükü uygulamalarının etkisini belirlemek amacıyla; süren göz sayısı, doğuş oranı, salkım sayısı, verim, salkım ve tane ağırlığı ile suda çözünebilir kuru madde (SÇKM), asitlik, $\mathrm{pH}$ ve antioksidan aktivite özellikleri incelenmiştir.

Hasat tarihi asmadaki salkımların \%50-60'ında çeşide özgü renk ile tat refraktometre ile saptandığında kaydedilmiştir. Derim tarihi 2013 yılında 22 Haziran, 2014 yılında 19 Haziran, 2015 yılında 30 Haziran olarak kaydedilmiştir.

Doğuş Oranı (\%): Bu oran her omcadaki süren göz sayısının, budamada bırakılan göz sayısına oranı olarak alınmıştır.

Toplam Salkım Sayısı (n omca-1): Bir omcadaki tüm salkımların sayılması yoluyla bulunmuştur.

Üzüm Verimi $\left(\mathrm{g}\right.$ omca $\left.^{-1}\right)$ : Bir asmadaki salkım sayısı ile ortalama salkım ağırlığının çarpılması yoluyla saptanmıştır.

Salkım Ağırlığı (g): Bir asmadan hasat edilen rastgele 10 salkım tartılarak ortalaması alınmıştır. 
Tane Ağırlığı (g): Tane ağırlığ 1 değeri her uygulamaya ait omcalardan hasat edilen 10 salkımdan rastgele alınan 100 adet tanenin ortalaması olarak saptanmıştır.

SÇKM (\%): Salkımlardan rastgele alınan 100 adet tanenin şırasından refraktometre ile kaydedilmiştir.

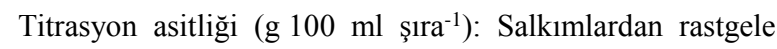
alınan 100 adet tanenin şırasından $0.1 \mathrm{~N} \mathrm{NaOH}$ kullanılarak titrasyon yöntemiyle bulunmuştur.

$\mathrm{pH}$ : Salkımlardan elde edilen şırada $\mathrm{pH}$ metre ile ölçülmüştür.

Antioksidan Aktivite Analizi: Üzüm örneklerinde antioksidan aktivite analizi DPPH (2,2-diphenyl-1picrylhydrazyl) serbest radikali kullanılarak yapılmıştır (Özden ve Vardin 2009; Kelebek ve ark. 2009). Antioksidan aktivite analizi denemenin ilk iki yılında elde edilen üzümlerde yapılmıştır.

Deneme parselinde bulunan omcaların kültürel işlemleri organik tarım kurallarına uygun şekilde yapılmıştır. Asmaların beslenmesi amacıyla organik bağcılıkta kullanım için sertifikalı ürünler kullanılarak uygun miktarlarda makro ve mikro elementlerin uygulanması gerçekleştirilmiştir. Omcaların azot ihtiyacını karşılamak için 8-10 kg da $\mathrm{kg}^{-1}$ hesabıyla sıra aralarına ekilmiş olan fiğ toprağa karıştırılmıştır. Power ve Zachariassen (1993), Ranells ve Wagger (1996), Mueller ve ThoroupKristensen (2001), Bair ve ark. (2008), Steinmaus ve ark. (2008), fiğin organik bağcılıkta mükemmel bir azot sağlayıcı olarak kullanıldığını ifade etmişlerdir.

Bağda ana fungal hastalıklardan külleme için kükürtlü; mildiyö için bakır içeren sertifikalı preparatlar kullanılmıştır. Ana zararlı salkım güvesi mücadelesinde spinosad etkili preparatlardan faydalanılmıştır.

Çalışma 5 tekerrürlü ve her tekerrürde 2 adet omca olacak şekilde düzenlenmiştir. Elde edilen verilere bölünmüş parseller deneme desenine uygun şekilde JMP 8.0 istatistik programı kullanılarak varyans analizi uygulanmış ve ortalamalar arasındaki farklılıklar Tukey testine göre belirlenmiştir. Farklı grupların saptanmasında $\% 5$ hata seviyesi dikkate alınmıştır.

\section{Bulgular ve Tartışma}

Çizelge 1'de verilen 3 yılın toplam göz sayısı, süren göz sayısı ve doğuş oranı değerlerinden terbiye şekilleri arasında bu bakımlardan farklılık bulunmazken süren göz sayıları $2 \mathrm{GY}$ uygulamasında daha yüksek çıkmıştır. Buna karşın 2015 yılında kontrol ve $1 \mathrm{GY}$ omcalarında doğuş oranının (sırasıyla \%95 ve \%93), 2GY uygulanan asmalardakinden (\%89) daha yüksek olduğu saptanmıştır.

Delice ve Çelik (2005), İtalia, Hafızali ve Kozak Beyazı üzüm çeşitlerinde uygun terbiye şeklinin belirlenmesine yönelik çalışmalarında çift kollu kordon ile rasyonel pergola terbiye şekline ait omcalarda kışlık gözlerin doğuş oranının \%70 ile \%100 arasında değiştiğini bildirmişlerdir. Trakya İlkeren çeşidinde kışlık gözlerde doğuş oranı T terbiye şeklinde $\% 83$ ile $\% 93$ değerleri arasında $\mathrm{Y}$ terbiye şeklinde ise $\% 84$ ve $\% 92$ oranında belirlenmiştir. Literatürde de belirtildiği gibi kışlık gözlerin doğuş oranı farklı terbiye şekline, budama tipine, asma üzerinde bulundukları pozisyona ve iklim koşullarına göre değişmektedir.

Çizelge 2 incelendiğinde çalışmanın ilk yılı (2013 yılı) itibariyle omcadaki toplam salkım sayısı bakımından yapılan varyans analizine göre istatistiksel olarak önemlilik kaydedilmemiştir. Denemenin 2. yılında ise toplam salkım sayısı bakımından sadece göz yükü seviyeleri önemli bulunmuş, 3. yıl verileri terbiye şekli ile göz yükü seviyelerinin de önemli olduğunu göstermiştir (Çizelge 2). Yapılan tüm uygulamalar değerlendirildiğinde fenolojik dönemler arasında çok fazla bir değişim belirlenmemiştir.

Çizelge 1. Trakya İlkeren çeşidinin T ve Y terbiye şekillerinde uygulanan farklı göz yükü seviyelerinin doğuş oranı (\%) üzerine etkisi. Table 1. The effect of Trakya Illkeren cultivar on the shooting rate (\%) of different bud load levels applied in the $T$ and $Y$ training.

\begin{tabular}{|c|c|c|c|c|c|c|c|c|c|c|}
\hline \multicolumn{2}{|c|}{ Uygulama } & \multicolumn{3}{|c|}{ Toplam göz sayısı (n) } & \multicolumn{3}{|c|}{ Süren göz sayısı (n) } & \multicolumn{3}{|c|}{ Doğuş oranı (\%) } \\
\hline Terbiye şekli & Göz yükü** & $2013^{Y}$ & 2014 & 2015 & 2013 & 2014 & 2015 & 2013 & 2014 & 2015 \\
\hline \multirow{3}{*}{$\mathrm{T}$} & Kontrol & 50 & 44 & 35 & 45 & 36 & 34 & 90 & 83 & 95 \\
\hline & $1 \mathrm{GY}$ & 51 & 36 & 31 & 48 & 29 & 29 & 93 & 83 & 95 \\
\hline & $2 \mathrm{GY}$ & 69 & 60 & 37 & 62 & 49 & 33 & 91 & 82 & 89 \\
\hline \multirow[t]{2}{*}{ Ortalama } & & 56 & 46 & 34 & 51 & 38 & 32 & 91 & 83 & 93 \\
\hline & Kontrol & 61 & 49 & 32 & 53 & 42 & 31 & 87 & 86 & 95 \\
\hline \multirow[t]{2}{*}{$\mathrm{Y}$} & $1 \mathrm{GY}$ & 45 & 30 & 28 & 40 & 27 & 26 & 89 & 88 & 92 \\
\hline & $2 \mathrm{GY}$ & 67 & 60 & 39 & 59 & 48 & 35 & 89 & 80 & 89 \\
\hline \multirow[t]{2}{*}{ Ortalama } & & 58 & 46 & 33 & 51 & 39 & 30 & 88 & 84 & 92 \\
\hline & Kontrol & 55 & 46 & $34 a b$ & $49 b$ & $39 b$ & $32 \mathrm{ab}$ & 89 & 84 & $95 \mathrm{a}$ \\
\hline \multirow[t]{2}{*}{ Göz yükü ort. } & $1 \mathrm{GY}$ & 48 & 33 & $29 b$ & $44 b$ & $28 \mathrm{c}$ & $27 \mathrm{~b}$ & 91 & 85 & $93 \mathrm{ab}$ \\
\hline & $2 \mathrm{GY}$ & 68 & 60 & $38 \mathrm{a}$ & $60 \mathrm{a}$ & $48 \mathrm{a}$ & $34 \mathrm{a}$ & 90 & 81 & $89 \mathrm{~b}$ \\
\hline D \%5 (T.Ş.) & & Ö.D. & Ö.D. & Ö.D. & Ö.D. & Ö.D. & Ö.D. & Ö.D. & Ö.D. & Ö.D. \\
\hline D \%5 (G.Y.) & & Ö.D. & Ö.D. & 4.10 & 8.30 & 6.27 & 4.19 & Ö.D. & Ö.D. & 4.83 \\
\hline D \%5 (T.ŞxG.Y.) & & Ö.D. & Ö.D. & Ö.D. & Ö.D. & Ö.D. & Ö.D. & Ö.D. & Ö.D. & Ö.D. \\
\hline
\end{tabular}

1GY: 1. Göz yükü seviyesi, 2GY: 2. Göz yükü seviyesi, **Tüm göz yükü uygulamalarında ilk $500 \mathrm{~g}$ çubuk ağırlığ için 20 ; sonraki her $500 \mathrm{~g}$ için K'da 10 ; $1 \mathrm{GY}$ 'de 5 ; 2GY'de 15 göz bırakılmıştır, Y: Aynı sütunda farklı harflerle gösterilen ortalamalar arasında istatistiki farklılık bulunmaktadır, Ö.D.: Önemli değil. 
Çizelge 2. Trakya İlkeren çeşidinin T ve Y terbiye şekillerinde uygulanan farklı göz yükü seviyelerinin toplam salkım sayısı ve verim üzerine etkisi. Table 2. The effect of Trakya Illkeren variety on the total cluster number and yield of different bud load levels applied in the $T$ and $Y$ training.

\begin{tabular}{|c|c|c|c|c|c|c|c|}
\hline \multicolumn{2}{|c|}{ Uygulama } & \multicolumn{3}{|c|}{ Salkım sayısı (n) } & \multicolumn{3}{|c|}{ Verim $\left(\mathrm{g} \mathrm{omca}^{-1}\right)$} \\
\hline Terbiye Şekli & Göz yükü** & $2013^{Y}$ & 2014 & 2015 & 2013 & 2014 & 2015 \\
\hline \multirow{3}{*}{$\mathrm{T}$} & Kontrol & 26 & 55 & 35 & 3753 & $12586 b$ & 12115 \\
\hline & $1 \mathrm{GY}$ & 43 & 54 & 32 & 8658 & 14184ab & 9547 \\
\hline & $2 \mathrm{GY}$ & 42 & 66 & 40 & 9990 & $18210 \mathrm{ab}$ & 15113 \\
\hline \multirow[t]{2}{*}{ Ortalama } & & 37 & 58 & 36a & $7467 b$ & 14993b & 12258 \\
\hline & Kontrol & 42 & 72 & 29 & 10486 & $23090 a$ & 11725 \\
\hline \multirow[t]{2}{*}{$\mathrm{Y}$} & $1 G Y$ & 37 & 49 & 25 & 7104 & $13237 \mathrm{ab}$ & 8558 \\
\hline & $2 \mathrm{GY}$ & 52 & 77 & 35 & 11648 & $21177 \mathrm{ab}$ & 13081 \\
\hline \multirow[t]{2}{*}{ Ortalama } & & 43 & 66 & $30 \mathrm{~b}$ & 9763a & 19168a & 11121 \\
\hline & Kontrol & 34 & $63 b$ & $32 \mathrm{ab}$ & $7119 b$ & $17838 b$ & $11920 \mathrm{~b}$ \\
\hline \multirow[t]{2}{*}{ Göz yükü ort. } & $1 \mathrm{GY}$ & 40 & $51 \mathrm{c}$ & $28 b$ & $7881 b$ & $13710 \mathrm{c}$ & $9052 \mathrm{c}$ \\
\hline & $2 \mathrm{GY}$ & 47 & $71 \mathrm{a}$ & $38 \mathrm{a}$ & $10845 \mathrm{a}$ & $19693 a$ & $14097 \mathrm{a}$ \\
\hline D \%5 (T.Ş.) & & Ö.D. & Ö.D. & 4.08 & 998.6 & 3235.3 & Ö.D. \\
\hline D \%5 (G.Y.) & & Ö.D. & 9.4 & 6.11 & 2979 & 3962.6 & 2689.9 \\
\hline D \%5 (T.ŞxG.Y.) & & Ö.D. & Ö.D. & Ö.D. & Ö.D. & 6998.5 & Ö.D. \\
\hline
\end{tabular}

1GY: 1. Göz yükü seviyesi, 2GY: 2. Göz yükü seviyesi, **Tüm göz yükü uygulamalarında ilk $500 \mathrm{~g}$ çubuk ağırlığı için 20; sonraki her 500 g için K'da 10, $1 \mathrm{GY}$ 'de 5 , 2GY'de 15 göz bırakılmıştır, Y: Aynı sütunda farklı harflerle gösterilen ortalamalar arasında istatistiki farklılık bulunmaktadır, Ö.D. : Önemli değil.

Çizelge 2'ye göre, Y terbiye şekli ve $2 \mathrm{GY}$ seviyesi uygulanan omcalardan daha yüksek üzüm verimi elde edilmiştir. 2013 yılı üzüm verimi bakımından terbiye şekli ve göz yükü seviyeleri istatiksel anlamda farklı bulunmuştur. 2014 yılında ise, terbiye şekli ve göz yükü seviyeleri ile interaksiyon önemli, 3. yıl verileri itibariyle ise yalnızca göz yükü seviyeleri arasındaki farklılıkların önemli olduğu saptanmıştır (Çizelge 2).

Trakya İlkeren çeşidinde üzüm veriminin farklı ve $2 \mathrm{GY}$ uygulamasında yüksek olmasının, kış budaması zamanında 2GY grubu omcalarda diğer göz yükü seviyelerine göre daha fazla süren göz sayısı elde edilmesine bağlı olarak daha fazla sürgün ve salkım sayısının elde edilmesinden kaynaklandığı düşünülmektedir.

Lenz-mozer, alçak kordon, pendelbogen ve Y şekillerinin omcalar üzerine etkisini araştıran Reynolds ve ark. (1996), Y terbiye şeklinde omca başına salkım sayısını ve buna bağlı verimi diğer terbiye şekillerine göre daha yüksek bulmuşlardır. Literatürde anıldığı gibi bizim araştırmamızda da $\mathrm{Y}$ terbiye şekline ait omcalarda salkım sayısı $\mathrm{T}$ terbiye şekline göre ilk iki yıl istatistiki önemde olmamakla birlikte yüksek çıkmış ve bu durum verime de yansımıştır. $\mathrm{Y}$ ve $\mathrm{T}$ terbiye şekilleri arasında salkım sayısı ve üzüm verimi açısından açıkça saptanamayan farklılık da bize deneme alanında kurulum maliyetleri dikkate alınarak iki şeklin de önerilebileceğinin işaretlerini vermiştir.

Çalışmamızda omca başına salkım sayısı daha fazla göz birak1lan $2 \mathrm{GY}$ grubuna ait omcalarda daha yüksek düzeyde elde edilmiştir. Polat ve Uzun (2007) ile Akın ve ark. (2012), araştırmalarında en yüksek verimi en fazla göz bırakılan omcalardan elde etmişlerdir. Ayrıca Y terbiye şeklinden alınan ortalama verim daha fazla saptanmıştır. Çelik (2003), Yuvarlak Çekirdeksiz üzüm çeşidinde farklı göz yükleri uygulamış ve fazla göz yükü uygulanan omcalardan ortalama 41.8 ile 46 adet salkım sayısı elde edilmiştir. Bu sonuçlar ile bizim çalışma verilerimiz benzerdir.

Dardeniz ve ark. (2007), tek kollu ve çift kollu kordon terbiye şekli verilen Müşküle üzüm çeşidinde salkım ağırlığı ile omca başına üzüm verimini daha fazla göz bırakılmış olan çift kollu kordon terbiye şeklinde daha yüksek düzeyde elde etmişlerdir. Bu sistemde ortalama salkım ağırlığı 377.8 g olarak, omca başına üzüm verimi ise ortalama $7391 \mathrm{~g}$ olarak belirlenmiştir.
Peterlunger ve ark. (2002), Pinot Noir üzüm çeşidinde basit guyot, çift guyot, yatay kordon ve dikey kordon terbiye şekillerini uygulayarak verim ve kalite özelliklerini incelemiştir. Farklı terbiye sistemlerine göre omca başına verim $0.9 \mathrm{~kg}-2.6$ $\mathrm{kg}$, salkım ağırlığ $18-94 \mathrm{~g}$, SÇKM \%17.5-18.0, pH 3.42-3.52, titrasyon asitliği 6.4-7.0 $\mathrm{g} \mathrm{L}^{-1}$ olarak kaydedilmiştir. Yatay kordon sistemi diğerlerine göre, verim, SÇKM ve titrasyon asitliği bakımından daha iyi sonuç vermiştir.

İşçi ve Altındişli (2014)'nin araştırmalarında organik olarak yetiştirilen Trakya İlkeren omcalarına farklı kültürel uygulamalar yapılmış ve Kontrol grubu omcalarında verim değerleri $8.02 \mathrm{~kg}$ ile $8.43 \mathrm{~kg}$ arasında elde edilmiştir. Bizim çalışmamızda ise üzüm verimi daha yüksek düzeyde belirlenmiştir. İşçi ve Gökbayrak (2014), yürüttükleri çalışmada Çift kollu Guyot terbiye şekli verilen Trakya İlkeren çeşidi Kontrol grubuna ait omcalarda üzüm verimini, 1. yıl $8.23 \mathrm{~kg}, 2$. y1 $8.02 \mathrm{~kg}$ olarak belirlemişlerdir. Verim değerlerinin bizim araştırmamızda, bu değerlerden daha yüksek düzeyde olduğu görülmektedir (Çizelge 2). Çelik (2003), Yuvarlak Çekirdeksiz üzüm çeşidiyle yapılan çalışmada fazla göz yükü uygulanan omcalardan ortalama $15.91 \mathrm{~kg}$ üzüm verimi alındığını bildirmiştir. $\mathrm{Bu}$ sonuçlar bizim verilerimizle benzerlik göstermektedir.

Çizelge 3'de görüldüğü üzere, Trakya İlkeren çeşidinde salkım ağırlığ $\mathrm{Y}$ terbiye şekli omcalarında 2014 yılı ölçümlerinde istatistiki olarak daha yüksek seviyede belirlenmiştir. Salkım ağırlığı bu şeklin verildiği asmalarda denemenin ilk yılında 210 g, 2. y1l 279.7 g ve 3. y1l 364.4 g olarak elde edilmiştir.

Denemenin 1. yılında salkım ağırlığı için yapılan varyans analizi sonuçlarına göre istatistiksel önemlilik olmadığ görülmektedir. 2014 y1lında terbiye şekli ile interaksiyon, denemenin 3. yıl verileri incelendiğinde ise yalnızca göz yükü seviyeleri açısından ortaya çıkmıştır (Çizelge 3).

Polat ve Uzun (2007), plastik serada yetiştirilen ve Y terbiye şekli verilen ve farklı asma şarjları uygulanan Trakya İlkeren çeşidinde, en yüksek salkım ağırlı̆̆ 12 (146 g) ve 18 (135 g) göz bırakılan asmalardan elde edilmiştir. Bizim çalışmamızda ise $\mathrm{Y}$ terbiye şekli verilen Trakya İlkeren çeşidinde salkım ağırlığ $210 \mathrm{~g}$ ile $364.4 \mathrm{~g}$ arasında belirlenmiştir. Akın ve ark. (2012), farklı ürün yükü seviyesi uyguladıkları çalışmalarında, en fazla verim ve salkım ağırlığı değerlerini daha çok göz bırakılan omcalardan elde etmişlerdir. 
İşçi ve Altundişli (2014), organik olarak yetiştirilen Trakya İlkeren üzüm çeşidi Kontrol grubuna ait omcalarında ortalama salkım ağırlığını 1. yıl $502.33 \mathrm{~g}, 2$. yıl ise $343.50 \mathrm{~g}$ olarak belirlemişlerdir.

Dardeniz ve ark. (2007), tek kollu ve çift kollu kordon terbiye şekli verilen Müşküle üzüm çeşidinde çalışmışlardır. Salkım uzunluğunun, çift kollu kordon terbiye şekline ait omcalardan elde edilen salkımlarda tek kollu kordon terbiye şeklinden elde edilenlerden daha fazla (ortalama $20.03 \mathrm{~cm}$ ) olduğunu saptamışlardır.

Denemenin her 3 yılında da 100 tane ağırlığı için yapılan analizlerin sonuçları bu bakımdan terbiye şekli ve göz yükü seviyeleri arasındaki farklılık ile interaksiyonun önemli çıkmadığını göstermiş̧tir (Çizelge 3).

Çizelge 4'de verilen SÇKM değerleri bakımından terbiye şekli ve göz yükü seviyeleri bakımından ortalamalar arasında önemlilik görülmemiştir. Titre edilebilir asitlik, denemenin 2. ve 3. yılında, en az sayıda gözün bırakıldığı $1 \mathrm{GY}$ uygulama omcalarından alınan salkım örneklerinde daha yüksek düzeyde çıkmıştır. Şıranın pH düzeyi üzerine uygulamaların önemli bir etkisi saptanmamıştır (Çizelge 4).

Polat ve Uzun (2007), serada yetiştirilen ve Y terbiye şekli verilen Trakya İlkeren çeşidinde yaptıkları çalışmada titre edilebilir asitlik \%0.8, SÇKM oranını ise \%15.2 olarak bulmuşken; bizim çalışmamızda titre edilebilir asitlik Y terbiye şeklinde ortalama $\% 0.507$ ve $\% 0.730$ arasında değişmiş, SÇKM düzeyi ortalama olarak \%16.9 ile \%18.2 arasında belirlenmiştir. İşçi ve Gökbayrak (2014), yürüttükleri çalışmada Çift kollu Guyot terbiye şekli verilen Trakya İlkeren çeşidi Kontrol grubuna ait üzümlerin SÇKM düzeylerini ortalama \%16.53, asitlik düzeyini ortalama $\% 0.696, \mathrm{pH}^{\prime} \mathrm{y}$ ise ortalama 3.67 olarak belirlemişlerdir. İşçi ve Altındişli (2014), farklı kültürel uygulamaların yapıldığı araştırmalarında, Trakya İlkeren çeşidi Kontrol grubu omcalarından elde edilen üzümlerin SÇKM düzeylerini 1. yıl ve 2. yıl sırasıyla; \%14.86 ile \%18.16, asitlik düzeyini $\% 0.351$ ile 0.526 , pH'y1 ise 3.63 ile 3.99 olarak kaydetmişlerdir. Tangolar ve ark. (2018), Trakya İlkeren üzüm çeşidinde SÇKM 'yi \%16.35, titre edilebilir asitlik düzeyini $\% 0.463, \mathrm{pH}$ 'yı ise 3.66 olarak bildirmişlerdir. Bu değerler bizim araştırma verilerimizi desteklemektedir.

Çizelge 3. Trakya İlkeren çeşidinin T ve Y terbiye şekillerinde uygulanan farklı göz yükü seviyelerinin salkım ve tane ağırlığı üzerine etkisi.

Table 3. The effect of Trakya Ilkeren cultivar on the bunch and berry weight of different bud load levels applied in the T and $Y$ training.

\begin{tabular}{|c|c|c|c|c|c|c|c|}
\hline \multicolumn{2}{|c|}{ Uygulama } & \multicolumn{3}{|c|}{ Salkım ağırlığg (g) } & \multicolumn{3}{|c|}{100 tane ağırlığı $(\mathrm{g})$} \\
\hline Terbiye şekli & Göz yükïi** & $2013^{Y}$ & 2014 & 2015 & 2013 & 2014 & 2015 \\
\hline \multirow{3}{*}{$\mathrm{T}$} & Kontrol & 139 & $226.8 b$ & 349.5 & 291 & 350.5 & 306.4 \\
\hline & $1 \mathrm{GY}$ & 234 & $259.5 \mathrm{ab}$ & 305.1 & 378 & 357.2 & 322.7 \\
\hline & $2 \mathrm{GY}$ & 222 & $262.7 \mathrm{ab}$ & 374.7 & 359 & 360.6 & 323.1 \\
\hline \multirow[t]{2}{*}{ Ortalama } & & 198 & $249.7 b$ & 343.1 & 343 & 356.1 & 317.4 \\
\hline & Kontrol & 214 & $309.6 \mathrm{a}$ & 399.4 & 354 & 374.6 & 374.9 \\
\hline \multirow[t]{2}{*}{$\mathrm{Y}$} & $1 \mathrm{GY}$ & 192 & $264.9 \mathrm{ab}$ & 330.1 & 370 & 367.5 & 311.5 \\
\hline & $2 \mathrm{GY}$ & 225 & $264.7 \mathrm{ab}$ & 363.9 & 369 & 325.1 & 311.6 \\
\hline \multirow[t]{2}{*}{ Ortalama } & & 210 & 279.7a & 364.4 & 364 & 355.7 & 332.6 \\
\hline & Kontrol & 176 & 268.2 & $374.4 \mathrm{a}$ & 322 & 362.5 & 340.6 \\
\hline \multirow[t]{2}{*}{ Göz yükü ort. } & $1 \mathrm{GY}$ & 213 & 262.2 & $317.6 \mathrm{~b}$ & 374 & 362.3 & 317.1 \\
\hline & $2 \mathrm{GY}$ & 223 & 263.7 & $369.2 \mathrm{a}$ & 364 & 342.8 & 317.3 \\
\hline D \%5 (T. Ş.) & & Ö.D. & 28.58 & Ö.D. & Ö.D. & Ö.D. & Ö.D. \\
\hline D \%5 (G.Y.) & & Ö.D. & Ö.D. & 42.29 & Ö.D. & Ö.D. & Ö.D. \\
\hline D \%5 (T.ŞxG.Y.) & & Ö.D. & 49.51 & Ö.D. & Ö.D. & Ö.D. & Ö.D. \\
\hline
\end{tabular}

1GY: 1. Göz yükü seviyesi, 2GY: 2. Göz yükü seviyesi, **Tüm göz yükü uygulamalarında ilk $500 \mathrm{~g}$ çubuk ağırlığ için 20 ; sonraki her $500 \mathrm{~g}$ için K'da 10 , $1 \mathrm{GY}$ 'de 5 , 2GY'de 15 göz bırakılmıştır, Y:Aynı sütunda farklı harflerle gösterilen ortalamalar arasında istatistiki farklılık bulunmaktadır, Ö.D.: Önemli değil.

Çizelge 4. Trakya İlkeren çeşidinin T ve Y terbiye şekillerinde uygulanan farklı göz yükü seviyelerinin şıra özellikleri üzerine etkisi.

Table 4. The effect of Trakya Illkeren variety on the characteristics of must of different bud load levels applied in the $T$ and $Y$ training.

\begin{tabular}{|c|c|c|c|c|c|c|c|c|c|c|}
\hline \multirow{2}{*}{$\begin{array}{c}\text { Uygulama } \\
\text { Terbiye şekli }\end{array}$} & \multicolumn{5}{|c|}{ SÇKM (\%) } & \multicolumn{2}{|c|}{ Asitlik (g $\left.100 \mathrm{~mL}^{-1}\right)$} & \multicolumn{3}{|c|}{$\mathrm{pH}$} \\
\hline & Göz yükü** & $2013^{Y}$ & 2014 & 2015 & 2013 & 2014 & 2015 & 2013 & 2014 & 2015 \\
\hline \multirow{3}{*}{$\mathrm{T}$} & Kontrol & 16.0 & 18.9 & 17.0 & 0.456 & 0.507 & 0.729 & 3.79 & $3.82 \mathrm{a}$ & 3.30 \\
\hline & $1 \mathrm{GY}$ & 16.9 & 18.1 & 16.9 & 0.463 & 0.532 & 0.766 & 3.75 & $3.75 \mathrm{~b}$ & 3.27 \\
\hline & $2 \mathrm{GY}$ & 16.5 & 18.0 & 16.8 & 0.484 & 0.516 & 0.673 & 3.73 & $3.73 b$ & 3.30 \\
\hline \multirow[t]{2}{*}{ Ortalama } & & 16.1 & 18.3 & 16.9 & 0.460 & 0.518 & 0.730 & 3.80 & 3.77 & 3.29 \\
\hline & Kontrol & 17.4 & 18.1 & 16.9 & 0.568 & 0.503 & 0.724 & 3.72 & $3.76 \mathrm{~b}$ & 3.33 \\
\hline \multirow[t]{2}{*}{$\mathrm{Y}$} & $1 \mathrm{GY}$ & 17.3 & 17.9 & 17.0 & 0.512 & 0.543 & 0.763 & 3.71 & $3.74 b$ & 3.36 \\
\hline & $2 \mathrm{GY}$ & 16.7 & 18.7 & 16.9 & 0.505 & 0.474 & 0.701 & 3.70 & $3.81 \mathrm{a}$ & 3.32 \\
\hline \multirow[t]{2}{*}{ Ortalama } & & 17.1 & 18.2 & 16.9 & 0.512 & 0.507 & 0.730 & 3.71 & 3.77 & 3.33 \\
\hline & Kontrol & 16.7 & 18.5 & 16.9 & 0.487 & $0.505 \mathrm{ab}$ & $0.730 \mathrm{ab}$ & 3.75 & 3.79 & 3.32 \\
\hline \multirow[t]{2}{*}{ Göz yükü ort. } & $1 \mathrm{GY}$ & 17.1 & 18 & 16.8 & 0.487 & $0.537 \mathrm{a}$ & $0.770 \mathrm{a}$ & 3.73 & 3.74 & 3.32 \\
\hline & $2 \mathrm{GY}$ & 16.6 & 18.3 & 16.9 & 0.494 & $0.495 b$ & $0.690 \mathrm{~b}$ & 3.71 & 3.77 & 3.31 \\
\hline D \%5 (T.Ş.) & & Ö.D & Ö.D. & Ö.D. & Ö.D. & Ö.D. & Ö.D. & Ö.D. & Ö.D. & Ö.D. \\
\hline D \%5 (G.Y.) & & Ö.D & Ö.D. & Ö.D. & Ö.D. & 0.028 & 0.05 & Ö.D. & Ö.D. & Ö.D. \\
\hline D \%5(T.ŞxG.Y.) & & Ö.D & Ö.D. & Ö.D. & Ö.D. & Ö.D. & Ö.D. & Ö.D. & 0.06 & Ö.D. \\
\hline
\end{tabular}

1GY: 1. Göz yükü seviyesi, 2GY: 2. Göz yükü seviyesi, **Tüm göz yükü uygulamalarında ilk $500 \mathrm{~g}$ çubuk ağırlı̆̆ için 20 ; sonraki her $500 \mathrm{~g}$ için K'da $10,1 \mathrm{GY}$ 'de 5 , 2GY’de 15 göz bırakılmıştır, Y:Aynı sütunda farklı harflerle gösterilen ortalamalar arasında istatistiki farklılık bulunmaktadır, Ö.D.: Önemli değil. 
Mulero ve ark. (2010)'nın organik yetiştirilen Monastrell üzüm çeşidi ile yaptıkları çalışmada titre edilebilir asitlik düzeyi

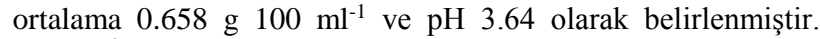
Trakya İlkeren çeşidinde $\mathrm{T}$ terbiye şeklinde asitlik düzeyi 0.460

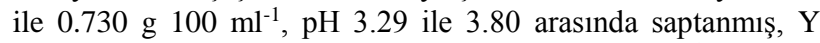

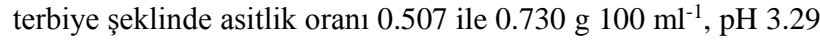
ile 3.80 değerleri arasında elde edilmiştir. Sonuçlarımız literatürle benzerlik göstermektedir.

Antioksidan aktivite bakımından Trakya İlkeren üzüm çeşidinde denemenin ilk yılında terbiye şekli ile göz yükü ortalamalar1; denemenin 2. y1lında interaksiyon önemli olarak kaydedilmiştir. Trakya İlkeren çeşidinde 2013 ve 2014 yıllarında antioksidan aktivite düzeyi T terbiye şeklinde $\% 94.20$ ile \%92.86 arasında değişirken; Y terbiye şeklinde \%93.59 ile \%93.21 olarak bulunmuştur. Trakya İlkeren çeșitlerinin antioksidan aktivite düzeyinin yüksek olduğu görülmektedir (Çizelge 5).

Çizelge 5. Trakya İlkeren çeşidinin $\mathrm{T}$ ve $\mathrm{Y}$ terbiye şekillerinde uygulanan farklı göz yükü seviyelerinin antioksidan aktivite üzerine etkisi.

Table 5. The effect of Trakya Ilkeren cultivar on the antioxidant activity (\%) of different bud load levels applied in the T and $Y$ training.

\begin{tabular}{|c|c|c|c|}
\hline \multicolumn{2}{|c|}{ Uygulama } & \multicolumn{2}{|c|}{ \% Antioksidan aktivite } \\
\hline Terbiye şekli & Göz yükü** & $2013^{Y}$ & 2014 \\
\hline \multirow{3}{*}{$\mathrm{T}$} & Kontrol & 92.01 & $94.08 \mathrm{ab}$ \\
\hline & $1 \mathrm{GY}$ & 93.25 & $94.44 \mathrm{a}$ \\
\hline & $2 \mathrm{GY}$ & 93.31 & $94.09 \mathrm{ab}$ \\
\hline \multirow[t]{2}{*}{ Ortalama } & & $94.20 \mathrm{a}$ & 92.86 \\
\hline & Kontrol & 93.64 & $93.62 \mathrm{ab}$ \\
\hline \multirow[t]{2}{*}{$\mathrm{Y}$} & $1 \mathrm{GY}$ & 92.90 & $94.42 \mathrm{a}$ \\
\hline & $2 \mathrm{GY}$ & 93.10 & $92.74 \mathrm{~b}$ \\
\hline \multirow[t]{2}{*}{ Ortalama } & & $93.59 \mathrm{~b}$ & 93.21 \\
\hline & Kontrol & $92.83 \mathrm{~b}$ & 93.85 \\
\hline \multirow[t]{2}{*}{ Göz yükü ort. } & $1 \mathrm{GY}$ & 93.07ab & 94.43 \\
\hline & $2 \mathrm{GY}$ & $93.21 \mathrm{a}$ & 93.41 \\
\hline D \%5 (T.Ş.) & & 0.48 & Ö.D. \\
\hline D \%5 (G.Y.) & & 0.59 & Ö.D. \\
\hline D \%5 (T.ŞxG.Y.) & & Ö.D. & 1.08 \\
\hline
\end{tabular}

Mulero ve ark. (2010), Monastrell üzüm çeşidinin organik ve konvansiyonel yetiştiriciliğinde denemenin 1. ve 2. yılında antioksidan aktivite düzeyini sırasıyla; $4.70 \mathrm{mM}$ Trolox $\mathrm{g}^{-1}$ ve $4.80 \mathrm{mM}$ Trolox g $^{-1} \quad$ ile $\quad 4.61 \mathrm{mM}$ Trolox g $^{-1}$ ve $3.99 \mathrm{mM}$ Trolox $\mathrm{g}^{-1}$ olarak kaydetmişlerdir. Araştırmanın 2 . yllında organik olarak yetiştirilen üzümlerde antioksidan aktivite, konvansiyonel yetiştirilen üzümlerden daha yüksek düzeyde elde edilmiştir. Du ve ark. (2012), Cabernet Sauvignon, Cabernet Franc, Merlot, Cabernet Gernischt, Muscat ile Red Globe üzüm çeşitlerinde antioksidan kapasite oranını sırasıyla $\% 92.77, \% 89.30, \% 89.91, \% 85.59, \% 90.83$ ve $\% 85.75$ olarak kaydetmişlerdir. Yıldırım ve ark. (2007)'nın yürüttükleri çalışmada organik olarak yetiştirdikleri Merlot üzüm çeşidinde antioksidan aktivite düzeyini \%86.55, Cabernet Sauvignon üzüm çeşidinde ise $\% 83.60$ bulmuşlardır. Bu değerler bizim bulgularımıza yakın değerler arasındadır.

\section{Sonuçlar}

$\mathrm{Bu}$ araştırmada, organik olarak yetiştirilen Trakya İlkeren üzüm çeşidinde $T$ ve $Y$ terbiye şekilleri ile üç farklı göz yükü seviyesi uygulamalarının üzümlerde verim ve kalite özelliklerine etkisi incelenmiştir. Çalışma sonucunda, Y terbiye şeklinin T terbiye şeklinden farklı olarak; üzüm verimi, salkım sayısı, salkım ve tane ağırlı̆̆ ile antioksidan aktiviteyi (\%) artırdığı belirlenmiştir. Göz yükü seviyeleri bakımından ise 2 GY uygulaması ile omcalarda daha yüksek düzeyde süren göz sayısı ve buna bağlı olarak verimin elde edilmesi sağlanmıştır. Y terbiye şekli ve 2 GY uygulamasıyla Trakya İlkeren çeşidinin verim ve kalite parametrelerinde artış kaydedilmiştir. Bu bulgulara dayanarak araştırmada öne çıkan Y terbiye şekli ile 2GY seviyesinin önerilebileceği sonucuna varılmıştır. Çalışmanın organik üzüm yetiştiriciliği koşullarında yapılmış olmasının da bu önerinin etkisini arttırdığı düşünülmektedir.

\section{Teşekkür}

$\mathrm{Bu}$ çalışma, ZF2013D2 proje numaralı Çukurova Üniversitesi Araştırma Projeleri Yönetim Birimi tarafından desteklenmiştir.

\section{Kaynaklar}

Ağaoğlu YS (1973) Sürgün Gelişme İstikametleri ile Çeşitli Sentetik Kimyasal Maddelerin Asma Tomurcuk Verimliliğine Etkileri Üzerine Bir Araştırma. Ankara Üniversitesi Ziraat Fakültesi Yayınları: 618. Bilimsel Araştırma ve İncelemeler: Ankara.

Ahmedullah M, Himmelrick DG (1990) Grape Management, Small Fruit Crop Management (Editors; D. G. Himmelrick. G. J. Galletta). The Haworth Press, 10 Alice Street Binghapton, Newyork, pp. 383-471.

Akın A, Dardeniz A, Ateş F, Çelik M (2012) Effects of various crop loads and fertilizer on grapevine yield and quality. Journal of Plant Nutrition 35: 1949-1957.

Bair KE, Davenport JR, Stevens RG (2008) Release of available nitrogen after incorporation of a legume cover crop in Concord Grape. Hortscience 43(3): 875-880.

Christensen LP, Leavitt GM, Hirschfelt DJ, Bianchi ML (1994) The effects of pruning level and post-budbreak cane adjustment on thompson seedless raisin production and quality. American Journal Enology Viticulture 45(2): 141-149.

Çelik M (2003) Yuvarlak Çekirdeksiz üzüm çeşidinde bazı anaç ve kültürel uygulamaların üzüm verimi ve kalitesi ile vegetatif gelişmeye etkileri üzerinde araştırmalar. Doktora Tezi, Adnan Menderes Üniversitesi Fen Bilimleri Enstitüsü, Aydın.

Çelik S (2007) Bağcılık (Ampeloloji). Namık Kemal Üniversitesi Ziraat Fakültesi Bahçe Bitkileri Bölümü Tekirdağ.

Dardeniz A, Kaynaş K, Gümüş R, Nazlım M, Kızılcık İ (2007) Umurbey-Çanakkale koşullarında yetiştirilen Müşü̈le üzüm çeşidinde (Vitis vinifera $L$.) farklı terbiye sistemlerinin üzüm verim ve kalitesine etkileri. Selçuk Üniversitesi Ziraat Fakültesi Dergisi 21(42): 11-15.

Delice A, Çelik S (2005) Italia üzüm çeşidinde iki farklı terbiye şeklinde sürgün gelişimi ile üzüm kalitesi arasındaki ilişkiler. Harran Üniversitesi Ziraat Fakültesi Dergisi 9(1): 43-52.

Du B, He BJ, Shi PB, Li FY, Li J, Zhu FM (2012) Phenolic content and antioxidant activity of wine grapes and table grapes. Journal of Medicinal Plants Research 6(17): 3381-3387.

Ergenoğlu F, Tangolar S, Gürsöz S (1991) Bazı üzüm çeşitlerinde farklı düzeylerde budamanın etkileri. Bahçe-Sera Dergisi 4: 27-30.

FAO (2020) Food and agriculture organization of the united nations. http://www.fao.org/faostat/en/\#data. Erişim 13 Ocak 2020.

Gök Tangolar S, Tangolar S, Tarım G, Kelebek H, Topçu S (2015) The effects of bud load and applied water amounts on the biochemical composition of the Narince grape variety (Vitis vinifera L.). Notulae Botanicae Horti Agrobotanici 43(2): 380-387. 
Howell GS, Miller DP, Edson CE, Streigler RK (1991) Influence of training system and pruning severity on yield, vine size and fruit composition of vignoles grapevines. American Journal of Enology and Viticulture 42(3): 191- 197

Index mundi (2019) Indexmundi. Com/Agriculture/?Country $=$ Za\&Commodity $=$

Grapes\&Graph=Production. Erişim 12 Temmuz 2019.

İşçi B, Altındişli A (2014) Organik olarak yetiştirilen Alphonse Lavalleé ve Trakya İlkeren (Vitis vinifera L.) cv. üzüm çeşitlerinde bazı kültürel uygulamaların verim ve kalite üzerine etkileri. Journal of Agricultural Faculty of Gaziosmanpasa University. Gaziosmanpaşa Üniversitesi Ziraat Fakültesi Dergisi 31(3): 91-100.

İşçi B, Gökbayrak Z (2014) Organik olarak yetiştirilen Alphonse Lavalleé ve Trakya İlkeren (Vitis vinifera 1 .) cv. üzüm çeşitlerinde bazı kültürel uygulamaların verim ve kalite üzerine etkileri (Journal of Agricultural Faculty of Uludag University). Uludağ Üniversitesi Ziraat Fakültesi Dergisi Cilt 28(1): 13-17.

Karataş H, Ağaoğlu S (2005) Asmalarda göz verimliliği. Alatarım 4(1): 13-22.

Kelebek H, Canbaş A, Selli S (2009) Effects of different maceration times and pectolytic enzyme addition on the anthocyanin composition of Vitis vinifera cv. Kalecik Karas1 wines. Journal of Food Processing and Preservation 33: 296-311.

Luque-Rodríguez JM, Luque de Castro MD, Perez-Juan P (2005) Extraction of fatty acids from grape seed by superheated hexane. Talanta 68(1): 126-130.

Mueller T, Thorup-Kristensen K (2001) N-Fixation of selected green manure plants in an organic crop rotation biological. Agriculture and Horticulture 18(4): 345-363.

Mulero J, Pardo F, Zafrilla P (2010) Antioxidant activity and phenolic composition of organic and conventional grapes and wines. Journal of Food Composition and Analysis 23: 569-574.

Özden M, Vardin H (2009) Şanlıurfa koşullarında yetiştirilen bazı şaraplık üzüm çeşitlerinin kalite ve fitokimyasal özellikleri. Harran Üniversitesi Ziraat Fakültesi Dergisi 13(2): 21-27.

Peterlunger E, Celotti E, Da Dalt, G Stefanelli, S Gollino G, Zironi R (2002) Effect of training system on Pinot Noir grape and wine composition. American Journal of Enology and Viticulture 53(1): 14-18.

Polat İ, Uzun Hİ (2007) Plastik serada yetiştirilen Trakya İlkeren üzüm çeşidinde farklı terbiye sistemi ve asma şarjı uygulamalarının erkencilik, verim ve kalite faktörleri üzerine etkileri. Ankara Üniversitesi Ziraat Fakültesi Dergisi 20(2): 289-300.

Power JF, Zachariassen JA (1993) Relative nitrogen utilization by legume cover crop species at three soil temperatures. Agronomy Journal 85: 134-140.

Ranells NN, Wagger MG (1996) Nitrogen release from grass legume cover crop monocultures and bicultures. Agronomy Journal 88: 777-782.

Reynolds AG, Wardle DA, Naylor AP (1996) Impact of training system vine spacing and basal leaf removal on Riesling, vine performance, berry composition, canopy microclimate and vineyard labor requirrements. American Journal of Enology and Viticulture 47(1): 63-75.

Steinmaus S, Elmore CL, Smith RJ, Donaldson D, Weber EA, Roncoroni JA, Miller PRM (2008) Mulched cover crops as an alternative to conventional weed management systems in vineyards. European Weed Research Society Weed Research 48: 273-281.

Tangolar S, Tangolar S, Tarım G, Ada G, Alkan Torun A, Karayaka M (2018) Bazı erkenci sofralık üzüm çeşitlerinde farklı dozlarda besin çözeltisi uygulamasının verim ve bazı kalite özelliklerine etkisi. Bahçe 47 (Özel Sayı 1: Türkiye 9. Bağcılık ve Teknolojileri Sempozyumu): 557-567.

Tarım ve Orman Bakanlığı (2019) Tarım ve orman bakanlığı web sitesi. http://www.tarim.gov.tr/Konular/Bitkisel-Uretim/OrganikTarim/Istatistikler. Erişim 01 Kasım 2019.

Tüik (2020) Türkiye İstatistik Kurumu. http://www.tuik.gov.tr/PreTablo.do?alt_id=1001. Erişim 15 Ocak 2020.

Winkler AJ, Cook JA, Kliewer WM, Lider LA (1974) General Viticulture. Univercity of California Press. Berkeley, Los Angeles and London.

Wongnarat C, Srihanam P (2017) Phytochemical and antioxidant activity in seeds and pulp of grape cultivated in Thailand. Orient Journal Chemistry 33(1): 113-121.

Yıldırım HK, Altındişli A, Akçay YD, Güvenç U, Sözmen EY (2007) Physical characteristics and antioxidant activities of organic grapes. Journal of Food Biochemistry 31: 81-95.

Zafrilla P, Morillas J, Mulero J, Cayuela JM, Martinez-Cacha A, Pardo F, Manuel J and Nicolas L (2003) Changes during storage in conventional and ecolojical wine: phenolic content and antioxidant activity. Journal Agriculture Food Chemistry 51: 4694-4700. 